document which was communicated to every member of that body, and the consideration of which formed part of its proceedings, can only by a legal fiction be described as confidential. But the plea that the document was confidential practically abandons the defence of it. A really statesmanlike paper on a matter which affects all the higher grade schools of the country would gain rather than lose by publicity.

The course which Convocation has under consideration has no doubt, as our correspondents point out, much to be said in its favour. But the reason actually put forward in the preamble of the Report as a ground for taking action, is from the point of view of public policy simply indefensible. It would be appropriate enough if the Report had been addressed by a Board of Directors to the shareholders of a Limited Liability Company, because in the fashion characteristic of such documents it treated the matter in hand from the strictly business point of view of the "concern." It is this attitude which we described as cynical. And we must repeat that it is not in our opinion decocous that a matter gravely affecting the higher education of the country should be treated simply as a question of the falling off of examiners at one particular centre of examination. If it is not the duty of a University to be dignified, it is at least the duty of its advisers to be statesmanlike; and if we may have done injustice to the real desires of the framers of the Report, they have only their own inadequate expression of them to blame. - ED.]

\section{Public Analysts}

In your last week's issue your correspondent, $\mathrm{M}_{\mathrm{r}}$. M. Williams, writes in such terms as would lead your readers to suppose that much less has been done in the matter of butter analysis than is really the case.

I have not the letter before me at this moment, and therefore speak from memory, but I believe that your readers are led to iniderstand that no analyses of pure butter and of pure butter mixed with known quantities of foreign fats have been published. In this he is mistaken, for in a little work published in 1874 , the details of eleven experiments upon butters known to be pure are given. The samples were purchased from outlying country farms in the Isle of Wight, and the results of the analyses fairly prove the constancy of the fixed fatty acids in butter.

It is also shown that all foreign fats likely to be used as adulterants are constant in their composition, and that they yield a much larger percentage of fixed acids than does butter; the range of difference being wide enough to offer a practical basis upon which to found accurate estimations of foreign fats in factitious butters. Many admixtures were made, and the published results of the analyses prove the practicability of the method employed. Your correspondent hints that no one dares to undersake the analysis of mixtures of known constitution. I ven: ture to state that if the necessary provisions could be made against concoctions chemically prepared, and so as to admit of commercial admixtures only, such as would be likely to be made use of by fraudulent butter factors, there would be no difficulty in getting half-a-dozen or more analysts ready to take up the gauntlet.

Southampton, Feb. 7

\section{Large Meteors}

A IARGE frreball was seen here this evening at about 7.35 P.M. It rolled slowly across the southern sky, and its path was slightly descending from left to right. The observed part of its course was from $\gamma$ Orionis to a few degrees below $a$ Ceti. There was no train, but the moon was shining brightly at the time, ancl may have overpowered any faint appendage of this sort. It was many times brighter than Venus (then near setting), and estimated to equal one-fifth the moon's apparent diameter. The globular form of the nucleus was very evident.

A meteor with very slow motion and a short course was observed on Feb. 2, 8.3 I P.M., traversing a space between $\delta$ Leonis and Cor Caroll, or just above Coma Berenicis. It was as bright as Mars. Radiant point probably near $\gamma$ Leonis, and very possibly a member of the same system as the fireball described above, which also appears to have been directed from Leo.

A bright meteor was also seen here on Jan. 3I, 9. I3 P.M. It fell almost vertically in S.S.W. from the Hyades, and must have been quite equal to Venus. I saw it in a region of the sky covered with thin clouds sufficiently dense to obscure the stars. Radiant point probably just north of $\alpha$ Tauri.

Ashley Down, Bristol, Feb. 5 William F. Denning

\section{The Flame of Common Salt}

I SEE that it is sometimes permitted to ask questions in NATURE for information. If I might be allowed to do so, I would ask why common salt gives a blue light when cast into a fire of coal, and a yellow light when burried on the wick of a spirit lamp? The books I have consulted do not give the reason of this.

E. G.

\section{OUR ASTRONOMICAL COLUMN}

The Binary Star $\eta$ Cassiopee.-Dr. Doberck, of Col. Cooper's Observatory, Markree Castle, has communicated to the Royal Irish Academy the results of a complete discussion of the elements of this binary from the measures to 1875 . Though he does not consider the exactness of the orbit to be great, partly owing to the observations being rather unfavourably placed, and partly to uncertainty in the observed distances, the agreement with observation is pretty close, and it appears likely that preference may be given to his elements, over those lately given by $\mathrm{D} r$. Duner, if the latter are correctly printed. Dr. Doberck's orbit is as follows, being the result of a sixth approximation :-

\begin{tabular}{|c|c|c|c|c|c|}
\hline Peri-astron passage & & $\cdots$ & & & 1909.24 \\
\hline & & & $\ldots$ & $\cdots$ & $39^{\circ} 57^{\prime}$ \\
\hline $\begin{array}{l}\text { Peri-astron from nod } \\
\text { Inclination ... }\end{array}$ & & & $\cdots$ & $\cdots$ & $223^{\circ} 20^{\prime}$ \\
\hline $\begin{array}{l}\text { Inclination ... } \\
\text { Excentricity }\end{array}$ & $\cdots$ & & $\cdots$ & $\ldots$ & $53^{\circ} 50^{\prime}$ \\
\hline $\begin{array}{l}\text { Excentricity } \\
\text { Semi-axis major }\end{array}$ & & & $\cdots$ & $\cdots$ & 0.5763 \\
\hline $\begin{array}{l}\text { Semi-axis major } \\
\text { Period of revolution }\end{array}$ & . & & $\cdots$ & $\cdots$ & $\begin{array}{r}9^{\prime \prime} \cdot 83 \\
222 \cdot 435 y\end{array}$ \\
\hline
\end{tabular}

Combining these values for the semi-axis and length of revolution, with Mr. Otto Struve's parallax (O" $0^{\prime \prime}$ 54), we have the following figures :-

Semi-axis major $\quad \ldots \quad \ldots \quad 63.83$ earth mean distances.

Mass of system $\quad \ldots \quad \ldots \quad 5.25$ sun-masses.

The parallax corresponds to a distance of $1,340,000$ times the mean distance of the earth from the sun. The uncertainty attending the measures of distance of the components and the amount of probable error of Mr. O. Struve's value of the parallax, of course allows only of the above figures being regarded as first rough approximations. The semi-axis of the orbit of $\eta$ Cassioper, it will be seen, results more than twice as great as that of the orbit of Neptune.

The star will doubtless be frequently measured in the present approach to the peri-astron, and every additional five years' observations rnust be of service in the improvement of the elements.

Dr. Doberck promises an investigation of the orbit of the close binary $\omega$ Leonis, no one of the orbits of which star, so far published, represents recent measures. Notwithstanding the case is a troublesome one for calculation, a very fair approximation to the elements should now be practicable.

The Rughy (Temple Observatory) Catalogue of DOUBLE STARS.-Following the excellent plan pursued by $\mathrm{Mr}$. J. Gurney Barclay in the speedy publication of the Leyton measures of double-stars, made by Mr. Talmage with the fine ten-inch refractor of that observatory, Mr. J. M. Wilson and Mr. G. M. Seabroke have given to astronomers (Memoirs, R.A.S., vol. xlii.) a catalogue of micrometrical measures of these objects made at the Temple Observatory of Rugby School during the years 1871-74, with the $8 \frac{1}{4}$-inch Alvan Clark refractor, constructed for the late Rev. W. R. Dawes, used by him in his later measures, and now the principal instrument of the Rugby establishment. Working in this interesting branch of astronomy, in co-operation with $\mathrm{Mr}$. E. Crossley's Observatory near Halifax, Rugby has occupied itself upon the even-numbered stars of Struve's Catalogue below $50^{\circ} \mathrm{N}$. declination, Mr. Crossley, with Mr. Gledhill, having employed his $9 \frac{1}{3}$-inch refractor upon other stars.

The Dawes-refractor is well spoken of by the Rugby 